\title{
PROFIL KONDISI FISIK PEMAIN SEPAK BOLA SMA NEGERI 1 KAUR
}

\author{
Leo Azidman \\ Universitas Bengkulu \\ Leoadziman@gmail.com \\ Arwin \\ Universitas Bengkulu \\ Syafrial \\ Universitas Bengkulu
}

\begin{abstract}
Abstrak
Penelitian ini bertujuan untuk mengetahui kondisi fisik pemain sepak bola SMA Negeri 1 Kabupaten Kaur. Kondisi fisik pemain sangatlah penting untuk mencapai prestasi yang maksimal. Penelitian ini merupakan penelitian survei dengan desain deskriptif. Subyek dari penelitian ini adalah seluruh pemain sepakbola SMA Negeri 1 Kabupaten Kaur, yaitu yang berjumlah 20 orang. Dalam penelitian ini menggunakan tes untuk mengetahui daya tahan, kecepatan, kelincahan dan kelentukan kaitanya dengan kondisi fisik pemain sepakbola. Teknik pengumpulan data menggunakan teknik tes dan pengukuran kondisi fisik. Instrumen dalam penelitian ini meliputi tes Lari 1200 yard, lari 60 yard, shuttle run, dan sit and reach.. Teknik analisis data yang digunakan dalam penelitian ini adalah dengan perhitungan statistik menggunakan analisis deskriptif persentase. Hasil penelitian yang diperoleh bahwa kondisi fisik keseluruhan pemain sepakbola SMA Negeri 1 Kabupaten Kaur adalah kurang. Dari 4 item tes yang dilaksankan, ternyata kondisi fisik pemain sepakbola SMA Negeri 1 Kaur semuanya memperoleh kategori kurang, kecuali pada tes sit and reach yang memperoleh kategori sedang.
\end{abstract}

Kata Kunci: Kondisi fisik, Pemain Sepakbola.

\begin{abstract}
This research aimed to know the physical condition of football players in senior high school number 1 kaur. This research was a survery research with descriptive design. The subjects of this research were all of the football players in senior high school number 1 kaur, that was 20 players. This reaserch used test tukeno the durability, rapidity, agility, flexsiblity, is connection with the physical condition of football players. Data collection tehcnique used test technique and physical condition measurements. The instruments of this research included 1200 yard run testing go yard run, shuttle run and sit and reach. Data analysis technique which was used in this research was statistical calculation by using descrivtive analysis persentages. The results of this research sowet that the overall phsycal condition of football players in senior high school number 1 kaur was less. Of the 4 items tested, it turns out the physical condition of football players in senior high school number 1 kaur all get less category, except on the test sit and reach that obtained the moderate category.
\end{abstract}

Keywords: Physical Condition, Football Players 


\section{PENDAHULUAN}

Dalam Undang-Undang Republik Indonesia No. 3 Tahun 2005 Tentang Sistem Keolahragaan Nasional Pasal 4 berbunyi: "Keolahragaan nasional bertujuan memelihara dan meningkatkan kesehatan dan kebugaran, prestasi, kualitas manusia, menanamkan nilai moral dan akhlak mulia, sportivitas, disiplin, mempererat dan membina persatuan dan kesatuan bangsa, memperkukuh ketahanan nasional, serta mengangkat harkat, martabat, dan kehormatan bangsa". SMA Negeri 1 Kaur adalah sekolah SMA Negeri yang terletak di JL. Sekunyit Bintuhan Provinsi Bengkulu, Kaur. SMA Negeri 1 Kaur adalah sekolah yang sering mengikuti berbagai kejuaraan dibidang akademik maupun non akademik di tingkat provinsi maupun nasional. Untuk di bidang non akademik sendiri yaitu di bidang olahraga SMA Negeri 1 Kaur selalu mengirimkan wakilnya di tiap kejuaraan terutama Sepakbola, Hal ini dapat di lihat dari banyaknya kejuaraan Sekolah Lanjutan Tingkat Atas (SLTA) tingkat kabupaten yang dimenangkan oleh SMA Negeri 1 Kaur. Akan tetapi untuk tingkat provinsi Bengkulu SMA Negeri 1 Kaur masih belum mampu meraih hasil yang maksimal karena belum pernah sekalipun menjadi juara. Berdasarkan pengamatan peneliti yang didampingi oleh pelatih Sepakbola SMA Negeri 1 Kaur.

Salah satu kendala Kurangnya prestasi SMA Negeri 1 Kaur diduga karena faktor kondisi fisik masih belum optimal. Hal ini terlihat ketika sedang mengikuti latihan pertandingan pemain inti melawan pemain cadangan, game berlangsung kurang lebih sekitar 70 menit (35 menit 1 bbk). Pemain sangat kuat pada 15-30 menit dan tempo permainan cepat, tetapi pada bbk kedua permainan lambat dan tempo permainan pun menurun. Bertolak dari uraian di atas, maka permasalahan tersebut harus dicarikan solusinya, sebab jika hal ini dibiarkan maka prestasi maksimal yang diharapkan akan sulit untuk di raih. Untuk itu penulis tertarik untuk melakukan penelitian tentang: "Profil Kondisi Fisik Pemain Sepak Bola SMA Negeri 1 Kaur". Olahraga berasal dari dua suku kata, yaitu olah dan raga, yang berarti memasak atau memanipulasi raga dengan tujuan membuat raga menjadi matang Olahraga digunakan untuk segala jenis kegiatan fisik, yang dapat dilakukan di darat, air, maupun di udara. Menurut Harsono (1988) dalam Husdarta (2013 : 150) mengemukakan bahwa olahraga pada hakikatnya adalah "the big muscles activies". Hampir sama dengan pendapat Kemal dan Supandi (1990) dalam Husdarta (2013) yang menjelaskan bahwa olahraga pada hakikatnya adalah "aktivitas otot besar yang menggunakan energi tertentu untuk meningkatakan kualitas hidup". Sedangkan menurut Dini Rosdiani (2013: 61) Olahraga adalah setiap aktivitas yang mengandung sifat atau ciri permainan dan melibatkan unsur perjuangan mengendalikan diri sendiri atau orang lain atau konfrontasi dengan dengan faktor alam.

Sepak bola merupakan cabang olahraga yang sangat populer di dunia dan olahraga ini sangat mudah dipahami. Alasan daya tarik sepak bola terletak pada kealamian permainan tersebut. Sepak bola adalah permainan yang menantang secara fisik dan mental, kita harus melakukan gerakan yang terampil dibawah kondisi permainan yang waktunya terbatas (Abdul Rohim, 2008:2). Pada tanggal 21 Mei 1904 berdirilah federasi sepak bola dunia yang disingkat FIFA (Federation Internasional The Football Association). Di Indonesia, organisasi yang menaungi sepak bola adalah PSSI (Persatuan Sepak Bola Seluruh Indonesia). PSSI berdiri pada tanggal 19 April 1930. Permainan sepak bola dimainkan oleh dua regu yang setiap regunya terdiri atas 11 orang pemain 
termasuk penjaga gawang. Permainan sepak bola dipimpin oleh seorang wasit dan dibantu dua hakim penjaga garis. Lama permainan sepak bola adalah $2 \times 45$ menit dengan istirahat 15 menit, lapangan permainan empat persegi panjang, panjangnya tidak boleh lebih dari 120 meter dan tidak boleh kurang dari 90 meter, sedang lebarnya tidak boleh lebih dari 90 meter dan tidak boleh kurang dari 45 meter (dalam pertandingan internasional panjangnya lapangan tidak boleh lebih dari 110 meter dan tidak boleh kurang dari 100 meter, sedang lebarnya tidak lebih dari 75 meter dan tidak boleh kurang dari 64 meter). Untuk bermain sepak bola dengan baik pemain dibekali dengan keterampilan gerak dasar atau teknik dasar yang baik. Pemain yang memiliki teknik dasar yang baik cenderung dapat bermain sepak bola dengan baik pula.

Beberapa keterampilan gerak dasar yang perlu dimiliki pemain sepak bola adalah Menendang (kicking), Mengontrol/menghentikan bola (controling), Menggiring bola (dribbling), Menyundul bola (heading), Merampas (tackling), Lemparan ke dalam (throw-in), Gerak tipu Teknik penjaga gawang (goal keeping). Selain diperlukan teknik dan taktik yang baik, kondisi fisik seorang pemain juga perlu diketahui. Seorang pemain juga harus bisa menjaga dan mengatur kondisi fisiknya agar tenaga yang dikeluarkan saat bermain bisa efektif dan efisien, sehingga tidak mudah lelah serta mampu melakukan teknik gerakan dengan tepat. Menurut Sneyers (1988: 3) dalam Wahyu Lestari (2013) prinsip dalam sepak bola sederhana sekali yaitu membuat gol dan mencegah agar jangan sampai lawan berbuat hal yang sama terhadap gawang sendiri. Berdasarkan prinsip tersebut dapat diketahui bahwa tujuan utama permainan sepakbola adalah mencetak gol ke gawang lawan sebanyak-banyaknya dan berusaha menggagalkan setiap serangan dari lawan yang ingin memasukkan bola ke gawangnya dengan sportif, tidak bertentangan dengan peraturan yang berlaku.

\section{METODE}

Metode yang digunakan dalam penelitian ini adalah metode survei dengan menggunakan teknik tes dan pengukuran dengan jumlah subjek sebanyak 20 pemain sepakbola SMA Negeri 1 Kaur. Instrumen yang digunakan dalam penelitian ini adalah menggunakan item tes dari pusat pengembangan kualitas jasmani (2010) dan Arsil, evaluasi penjas dan olahraga (2010), yang terdiri dari 4 item tes yaitu: 1) lari 60 meter 2) shuttle run 3) sit and reach 4) lari 1200 meter.

Data yang terkumpul dianalisis dengan deskriptif presentase, adapun rumusnya yaitu:

$$
\begin{aligned}
& \mathrm{P}=\frac{F}{N} \times 100 \% \\
& \text { Keterangan: } \\
& \mathrm{P}: \text { Presentase } \\
& \mathrm{f}: \text { Frekuensi } \\
& \mathrm{N}: \text { Jumlah Sampel } \\
& \text { Wahyu Lestari (2013) }
\end{aligned}
$$

\section{HASIL DAN PEMBAHASAN}

Penelitian ini menggunakan tes dan pengukuran terhadap 4 tes fisik yang digunakan untuk menunjang kemampuan fisik bagi pemain sepakbola. Teknik analisis data yang digunakan untuk menguji data dalam penelitian ini adalah analisis deskriptif persentase. Dimana hasil dari data penelitian dihitung dalam jumlah persen berapa pemain yang dalam katagori baik sekali, baik, sedang, kurang dan kurang sekali.

1. Kondisi Fisik Keseluruhan

Tingkat kondisi fisik pemain sepakbola SMA Negeri 1 Kaur secara keseluruhan yang berjumlah 20 orang yaitu; 7 orang pemain masuk kategori sedang 
(35\%) dan 13 orang pemain masuk kategori kurang (65\%).

2. Lari 60 meter

Hasil tes pengukuran lari 60 meter terhadap 20 pemain yaitu; 2 pemain masuk kategori baik (10\%), 10 pemain masuk kategori sedang (50\%), dan 8 pemain masuk kategori kurang (40\%).

3. Shuttle run

Hasil tes pengukuran shuttle run test terhadap 20 pemain yaitu; 2 pemain masuk kategori baik yaitu 10\%, 6 pemain masuk kategori sedang (30\%), 7 pemain masuk kategori kurang (35\%), dan 5 pemain masuk kategori kurang sekali (25\%).

4. Sit and reach

Hasil tes pengukuran sit and reach terhadap 20 pemain yaitu; 7 pemain masuk kategori baik (35\%), 9 pemain masuk kategori sedang (45\%), 7 pemain masuk kategori kurang (35\%), dan 4 pemain masuk kategori kurang sekali (20\%).

5. Lari 1200 meter

Hasil tes pengukuran lari 1200 meter terhadap 20 pemain yaitu; 4 pemain masuk kategori baik (20\%), 9 pemain masuk kategori sedang (45\%), 7 pemain masuk kategori kurang (35\%).

\section{PENUTUP}

\section{Simpulan}

Setelah dilakukan analisis data penelitian mengenai kondisi fisik pemain sepakbola SMA Negeri 1 Kaur maka dapat diambil kesimpulan bahwa kondisi fisik secara keseluruhan pemain sepakbola SMA Negeri 1 Kaur termasuk dalam kategori kurang.

\section{Saran}

1. Bagi pemain sepakbola SMAN 1 Kaur, latihan secara ruitn dan teratur dengan baik, para individu dan team harus mempunyai tujuan yang terencana untuk untuk mencapai hasil yang maksimal terutama masalah kondisi fisik pemain. Apabila latihan itu selalu dilakukan, dan pemain itu melakukan latihan dengan sungguh-sungguh dengan program latihan yang baik, maka seorang pemain bisa memiliki kondisi fisik yang bagus.

2. Untuk pelatih, disarankan untuk menambah program latihan fisik dan membuat program latihan yang teratur dan terencana, supaya para pemain sepakbola SMA Negeri 1 Kaur memiliki kondisi fisik yang bagus.

3. Bagi peneliti yang akan datang agar dapat mengadakan pertimbangan penelitian ini dengan menggunakan subyek yang lain, baik dalam kuantitas maupun tingkatan kualitas.

\section{DAFTAR PUSTAKA}

Abdul Rohim. (2008). Bermain Sepak Bola. Aneka Ilmu: Semarang

Arsil. (2010). Evaluasi Penjas dan Olahraga. Padang

Dini Rosdiani. (2013). Dinamika Olahraga dan Pengembangan Nilai. Alfabeta: Bandung

Ericka Pramadinata. (2015). Kontribusi Kelincahan Tubuh Terhadap Keterampilan Round Off Pada Senam Lantai Artistik Siswa Kelas V SD Negeri 55 Kota Bengkulu (Skripsi). Bengkulu :UNIB.

Harsono. (1988). Coaching dan Aspekaspek Psikologis Dalam Coaching. Jakarta

Husdarta. (2013). Sejarah dan Filsafat Olahraga. Alfabeta: Bandung

Pusat Pengembangan Kualitas Jasmani (2010). Tes Kesegaran Jasmani Indonesia. Jakarta

Richad. (2010). Berlatih Kebugaran Jasmani. Citraunggul Laksana: Jakarta Timur 
Undang-Undang Negara Republik Indonesia No.3 (2005). Sistem Keolahragaan Nasional. Jakarta. Menpora.

Wahyu Lestari. (2013). Profil Kondisi Fisik Pemain Sepak Bola Putri Binangun Kulon Progo (Laporan Penelitian). Yogyakarta. 